\title{
DEVELOPMENT OF CRITERIA FOR SEISMIC REVIEW OF SELECTED NUCLEAR POWER PLANTS
}

N. M. Newmark

W. J. Hall

\begin{abstract}
Manuscript Completed: May 1978 Date Published: May 1978
\end{abstract}

N. M. Newmark Consulting Engineering Services

1211 Civil Engineering Building Urbana, IL 61801

This document is PUBLICLY RELEASABLE Bamstena

Authorizing Official

Date: $7-30.07$
Division of Operating Reactor Office of Nuclear Reactor Regulation U. S. Nuclear Regulatory Commission Under Contract No. AT(49-24)-0116 


\section{DISCLAIMER}

This report was prepared as an account of work sponsored by an agency of the United States Government. Neither the United States Government nor any agency Thereof, nor any of their employees, makes any warranty, express or implied, or assumes any legal liability or responsibility for the accuracy, completeness, or usefulness of any information, apparatus, product, or process disclosed, or represents that its use would not infringe privately owned rights. Reference herein to any specific commercial product, process, or service by trade name, trademark, manufacturer, or otherwise does not necessarily constitute or imply its endorsement, recommendation, or favoring by the United States Government or any agency thereof. The views and opinions of authors expressed herein do not necessarily state or reflect those of the United States Government or any agency thereof. 


\section{DISCLAIMER}

Portions of this document may be illegible in electronic image products. Images are produced from the best available original document. 
TABLE OF CONTENTS

Page

I. INTRODUCTION . . . . . . . . . . . . . . . . . . . . I

1.1 General Philosophy Pertaining to Review Process ....... I

1.2 General Design and Analysis Concepts ........... 3

1.3 Scope of Report .................... 4

11. SELECTION OF EARTHQUAKE HAZARD FOR REVIEW AND DESIGN ...... 5

2.1 General Concepts . . . . . . . . . . . . . . . 5

2.2 Regional Motions, Including Propagation and Attenuation . . 6

2.3 Site Amplification and Modification.......... 9

2.4 Vertical Motions .................. 11

III. DESIGN SEISMIC LOADINGS . . . . . . . . . . . . . . . . 12

3.1 Actual versus Effective Earthquake Motions . . . . . . 12

3.2 Design Seismic Motion . . . . . . . . . . . . 13

IV. SOIL-STRUCTURE INTERACTION . . . . . . . . . . . . 15

V. DAMPING AND ENERGY ABSORPTION . . . . . . . . . . . . . . . . . 17

5.1 Implications of Damage or Collapse . . . . . . . . . 17

5.2 Damping . . . . . . . . . . . . . . . . . 17

5.3 Ductility................... 18

VI. METHODS OF DYNAMIC ANALYSIS . . . . . . . . . . . . . 20

6.1 Response Spectrum . . . . . . . . . . . . . . 20

6.2 Use of Response Spectra for Multi-Degree-of-Freedom

Systems -- Modal Analysis.... . . . . . . . . . 21

6.3 Time History Analysis... . . . . . . . . . 22 
VII. REVIEW ANALYSIS AND DESIGN PROCEDURES............... . . 24

7.1 General Considerations . . . . . . . . . . . . . 24

7.2 Modified Response Spectra . . . . . . . . . . . . . 24

7.3 Effects of Size and Weight of Structure . . . . . . . 25

7.4 Effects of Inelastic Action ............. . 27

7.5 Seismic Design Classification . . . . . . . . . . 27

7.6 Design Spectra . . . . . . . . . . . . . . 28

7.7 Combined Effects of Horizontal and Vertical Excitation . . 29

7.8 Unsymmetrical Structures, Torsion, Overturning and Uplift . 30

7.9 Response of Equipment and Attachments . . . . . . . 31

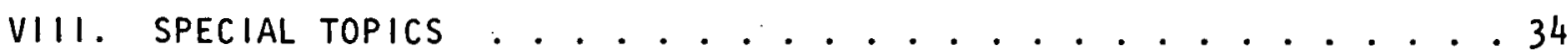

8.1 Fault Motions . . . . . . . . . . . . . . 34

8.2 Relative Motions............... . . 34

8.3. Underground Conduits and Piping . . . . . . . . . . 35

8.4 Tanks and Vaults.................. . . 36

8.5 Equipment Qualification . . . . . . . . . . . 37

8.6 Quality Control and Details of Construction ....... . 38

8.7 Probability Concepts................ . . 38

IX. SUMMARY REVIEW AND REPORTING .................. 40

9.1 Audit Procedure and Systems Surmary . . . . . . . . 40 REFERENCES ............................ 41 
Table Page

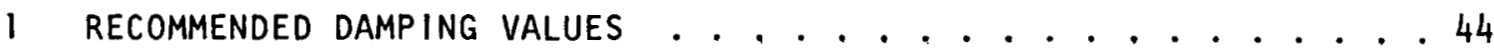

2 EQUATIONS FOR SPECTRUM AMPLIFICATION FACTORS FOR HORIZONTAL MOTION ............... 45

3 SPECTRUM AMPLIFICATION FACTORS FOR HORIZONTAL ELASTIC RESPONSE . . . . . . . . . . . . 45

4 PROPOSED SEISMIC DESIGN CLASSIFICATION ............ . 46

\section{LIST OF FIGURES}

Figure

I SIMPLE UNDAMPED MASS-SPRING SYSTEM . . . . . . . . . . . 47

2 RESISTANCE-DISPLACEMENT RELATIONSHIP . . . . . . . . . . 47

3 ELASTIC DESIGN SPECTRUM, HORIZ. MOTION, $(0.5 \mathrm{~g}$ MAX. ACCEL., 5\% DAMPING, ONE SIGMA CUM. PROBABILITY) . . . . . . . . . 48

4 DESIGN SPECTRA FOR EARTHQUAKES .................. 48

5 ELASTIC AND INELASTIC DESIGN SPECTRA . . . . . . . . . . . 49 


\section{INTRODUCTION}

\subsection{General Philosophy Pertaining to Review Process}

Many of the early nuclear facilities were designed and constructed during the time when seismic design procedures for such specialized systems were beginning to be developed. It is recognized that in many cases these plants were designed to criteria that are less rigorous than those used for recent plants. In view of the rapid development of the state-of-the-art of seismic design during the past two decades even some of the more modern plants, designed as recently as ten years ago, may need review in the light of current criteria and present knowledge.

The purpose of this report is to set forth seismic criteria and design concepts applicable to review analyses and upgrading for selected nuclear power plants, although the principles are applicable generally to older operating plants.

At the outset, it is expected that the review process would consist of two general tasks, one pertaining to detailed review of the existing plant in the light of applicable review criteria and the second involving detailed design and analysis studies to develop the desired (and possible) upgrading of the seismic resistance.

It is envisioned that the detailed review would encompass inspection of the plant, review of existing documentation (reports, plans, and calculations) as appropriate with identification of those systems which realistically and economically are amenable to upgrading. As a part of this review it may be desirable to carry out a risk analys is to help provide a basis for the decisions that must be made as to the desirability and 
advantages of carrying out the upgrading. Such studies also could be helpful in deciding on the timing of the upgrading program since in many cases it may not be possible to carry out the entire retrofit construction program during one time period.

It is well known that upgrading and retrofitting constitute expensive operations when they can be accomplished at all. In many cases it is economically, if not physically, impossible to carry out significant seismic upgrading improvements. In those cases where it is possible economically it is desirable to take advantage of the latest concepts pertaining to development of seismic resistance. Thus in the evaluation of the existing facility, and in the subsequent detailed design studies for physical upgrading of structural or mechanical systems, the authors believe it is possible (and desirable) to take into account the modest amount of nonlinear behavior that can be permitted in many portions of such systems without significant decrease in the margin of safety against safe shutdown or containment. A number of other concepts (in the sense of applications to nuclear facilities) are identified herein as well, including spectrum concepts for handling close-in versus distant earthquakes, and bounding of forces likely to be felt by equipment.

Last, but by no means least, is the observation that the inherent seismic resistance of well designed and constructed systems is usually much greater than that commonly assumed, largely because nonlinear behavior is mobilized to limit the imposed forces and accompanying deformations. For such systems where the resistance is nondegrading for reasonable deformations the requirements for retrofitting may be nonexistent or at most minimal. 


\section{I.2 General Design and Analysis Concepts}

When a structure or a piece of equipment or instrumentation is subjected to earthquake motions, its base or support tends to move with the ground on which it is supported or with the element on which it rests. Since this motion is relatively rapid, it causes stresses and deformations in the item considered. If this component is rigid, it moves with the motion of its base, and the dynamic forces acting on it are very nearly equal to those associated with the base accelerations. However, if the component is quite flexible, large relative motions or strains can be induced in the component because of the differential motions between the masses of the component and its base. In order to survive the dynamic motions, the element must be strong enough as well as ductile enough to resist the forces and deformations imposed on it. The required strength and ductility are functions of stiffness or flexibility, among other things. In assessing seismic effects it should be remembered that the seismic actions generally are in addition to those already existing, i.e., arising from dead load, live load, thermal effects, etc.

Unfortunately, the earthquake hazard for which an element or component should be designed is subject to a high degree of uncertainty. In only a few areas of the world are there relatively long periods of observations of strong earthquake motions. The effects on a structure, component, or element, depend not only on the earthquake motion to which it is subjected, but on the properties of the element itself. Among these properties, the most important are the energy absorption within it or at interfaces between the element and its support, either due to damping or inelastic behavior, its period of vibration, and its strength or resistance. 


\subsection{Scope of Report}

The report that follows contains a discussion of those criteria and principles which it is believed would be of primary concern in a review of an existing nuclear facility. The aim in preparing this summary has not been to discuss each topic in great depth but instead to place in perspective the points of engineering concern and to delineate the major i tems that should be considered in the review.

The text that follows begins with a general discussion of the earthquake hazard which should be used for the review. It is our belief that the seismic hazard should in general be re-evaluated for each existing plant with consideration of current NRC procedures. This section is followed by a section on seismic motions to be used in upgrading, damping and energy absorption, soil-structure interaction, and a brief discussion of methods of dynamic analysis. Thereafter follows a discussion of specific topics which must be considered in detail in the review process including such items as the material properties, load combinations, response spectra, uplift, and response of equipment.

The next section lists and discusses briefly a number of special topics which may need consideration as a part of the review, including fault motions, conduits, vaults and tanks, quality control and risk assessment. The report concludes with some observations on audits and systems summaries, specifically with reference to topics which should be examined as a part of the seismic review.

The material in the report is drawn in part from material previously prepared by the authors, but has been supplemented with much additional material reflecting our latest studies, understanding, and views particularly as they relate to review and upgrading. 


\section{SELECTION OF EARTHQUAKE HAZARD FOR REVIEW AND DESIGN}

\subsection{General Concepts}

The process of earthquake resistant review and design requires selection of earthquake hazards as well as estimates of structural strengths, either implicitly or explicitly, as an integral part of the review procedure. Unless these determinations are made in a consistent manner, the final design may be either grossly uneconomical or dangerously unsafe. Both sets of parameters are probabilistic in nature although, for convenience, many of the aspects of the determination of structural strength may reasonably be approximated as deterministic. However, the earthquake motions themselves for which the design review is to be accomplished, or even the occurrence itself of an earthquake affecting the site, must be considered as probabilistic. In the design of nuclear power plants under current criteria it is customary to provide resistance against two earthquakes: (1) a "maximum credible earthquake", which has only a small probability of occurrence during the lifetime of the plant, with a long return period for which the design is made at yield levels or limit strength conditions; and (2) an earthquake having a much higher probability of occurrence, with a return period shorter than that applicable in (1), often taken as half of the earthquake excitation defined in (1), for which the design is made at somewhat. lower allowable stresses and for somewhat different combinations of conditions. At present the Nuclear Regulatory Commission defines these earthquakes as the Safe Shutdown Earthquake (SSE) and the Operating Basis Earthquake (OBE) respectively. As part of the review process for existing plants it is recommended that a thorough investigation of the seismic hazard be made in accordance with 
criteria and Standard Review Plans currently employed by the NRC. In turn this hazard should be used consistently in the review evaluation in order to permit valid comparison against criteria and design as might be found in newly designed plants. Such comparisons will be required as part of the decision process concerning upgrading.

\subsection{Regional Motions, Including Propagation and Attenuation}

In general, two procedures are available to define the earthquake hazard. In the first where there is an extensive history of earthquake activity and geologic and tectonic investigations are feasible, estimates can be made of the possible magnitude and the location of future earthquakes affecting a site. In many instances, such earthquakes will occur along well defined faults. One can then make estimates of the earthquake motion intensity propagated to the site, taking into account the experimental and observational data available for this purpose as described for example in detail in Refs. 1 and 2.

Donovan (Ref. 1) plotted data at various distances for accelerations from 678 world earthquake records ranging in magnitude from less than 5 to greater than 8. He found a great deal of scatter, which he was able to reduce somewhat by normalizing the data to the exponential of one-half the magnitude. He was able to show also that the probability distribution of the data is logarithmic normal. For the median of the acceleration, a, measured in gravity units, g, Donovan derived a relation involving the hyperfocal range $R$, in $\mathrm{km}$, measured from the earthquake focus to the point on the ground surface where the record was taken in terms of the Richter magnitude $M$, as given by the following equation:

$$
a=1.10 e^{0.5 M}(R+25)^{-1.32}
$$


The geometric standard deviation, $\sigma$, designed as the ratio for the median plus one standard deviation value to the median value, was very nearly 2.0 , indicating that the spread in the data was quite large.

For data from 214 San Fernando records, Donovan obtained a larger attenuation and a smaller spread in the data, corresponding to the relationship (applying to the magnitude for this earthquake of 6.4 ):

$$
a=21.5 \mathrm{~g} \mathrm{e}^{6.4 / 2}(\mathrm{R}+25)^{-2.04}
$$

where the geometric standard deviation was determined to be 1.6 . This more rapid attenuation has been noted by others, and is consistent with the data reported in Ref. 2 .

In all cases, reference to the figures will show that only very limited data existed for earthquakes closer than about $20 \mathrm{~km}$ to the hypocenter. The only definitive study of close-in earthquake motion is that contained in Ref. 3 , and the most recent interpretation pertaining to close-in effects on nuclear plants is contained in Amendment 50 and companion NRC studies for the Diablo Canyon Plant.

The second procedure for developing the earthquake hazard in a region is used when occurrence of earthquake is not generally associated with surface faulting, or when insufficient data are available from records and observations... Under these conditions, relationships have been developed for correlating ground motions, generally maximum velocities or maximum accelerations, to a quallitative measure of the intensity of motion, as for example that of the "Modified Mercalli Intensity". Although these relations are not as readily subject to mathematical determination as the relations for earthquake shock propagation, there are sufficient observations to 
permit useful probabilistic data to be obtained. Such data are summarized in Refs. 4 and 5.

These data show even more scatter than those from accelerations and distance from the focus. They are complicated by the fact that the MM Intensity is a subjective measure in large part, and for higher levels of damage it depends to a great extent on type of building, properties of building materials, foundation conditions and the like; for these reasons, for example, one would expect some changes in damage assessment over scores of years as the quality of construction materials improved. Data from quarry blasting indicates that plaster cracking rarely begins at less than $0.5 \mathrm{in} / \mathrm{sec}$ maximum ground velocity and generally is quite prevalent for velocities greater than $2 \mathrm{in} / \mathrm{sec}$. Finally, the observation is made that in the El Centro earthquake of 1940, the maximum ground velocity was about $14 \mathrm{in} / \mathrm{sec}$, and the Modified Mercalli Intensity was reported as IX.

These and other data suggest that the median value of the maximum ground velocity can be inferred from the Modified Mercalli Intensity by using the relationship that the maximum ground velocity is approximately $8 \mathrm{in} / \mathrm{sec}$ for MM VIII and changes by a factor of 2 for each unit change in MM INtensity below MM VIII, but increases above this level more slowly. It is believed that this relationship correlates well with observations from all dynamic sources. By comparison of the acceleration and velocity with the relationship that a velocity of $48 \mathrm{in} / \mathrm{sec}$ corresponds to a $1 \mathrm{~g}$ maximum acceleration in competent soils, one obtains the result that for Modified Mercalli Intensity VIII, the acceleration is $0.167 \mathrm{~g}$ and changes by a factor of 2 with each unit drop in MM Intensity. These relationships should drop off somewhat from the factor of 2 increase as the intensity 
increases above VIII, however.

It is believed that the relationship between maximum ground velocity and MM Intensity is nearly independent of the properties of the soil, but the relationship between velocity and acceleration is slightly soil dependent and there may be some dependence of soil properties on the relationship for acceleration stated above. Nevertheless, the observations of MM Intensity are most strongly influenced by building type rather than by soil properties when intensity is associated with building damage. In other words, the soil type has implicitly been taken into account in the observation of damage or in the observational data leading to the MM Intensity reported.

\subsection{Site Amplification and Modification}

The regional motions that one derives from the methods described in the above must be modified to take account of the geologic and stratographic conditions pertaining to the site. Although there has been a great deal of study and research involved in this topic it must be considered still a controversial matter. Nevertheless, it is clear from observations that the type of soil or subsoil has a major influence on the motions that are recorded. In general, for the same earthquake, where the intensity is low (possibly maximum acceleration less than $0.2 \mathrm{~g}$, where $\mathrm{g}$ is the acceleration of gravity) the measured accelerations are generally higher on sediments than on rock. However, when the acceleration is high (greater than $0.2 \mathrm{~g}$ ), then the accelerations measured on rock appear to be higher than those on soil. In most instances the measured velocities are nearly the same. Studies of the nature of the motions on sites of different stiffnesses are 
summarized in Refs. 6 and 7 in terms of the so-called "response spectra" applicable to the measured records at various sites.

Although analytical methods have been proposed purporting to explain phenomena such as those described in the references previously cited, in most cases these analyses consider a condition not representative of actual conditions. The principal assumption (that the earthquake motions consist of horizontal shear waves propagated vertically upward from some base layer where the motions are defined) is contrary to observations.

For example, it is shown in Ref. 8, and it has long been considered, that for longer period motions, possibly where the periods are one second or longer, the motions are primarily due to surface waves such as Rayleigh waves or Love waves. It is quite likely, however, that for moderate distances, beyond those corresponding to the depth of focus, surface waves have an important effect even for higher frequencies or shorter period motions, and more complex motions must be considered other than those due to horizontal shears propagated vertically upward. Moreover, the fact that vertical motions occur cannot be accounted for by the simple horizontal shear wave model.

Considerations leading to variation in intensity of motion with depth beneath the surface are very complex. There are few data that directly relate surface motions to motions beneath the surface. The observational data for motions beneath the surface, compared with surface motions, includes two or three small earthquakes in Japan. These and other limited data indicate some reduction with depth of surface motion intensity, but for large motions or high intensities, they do not support the contention that one can compute accurately variations in intensities of motion with depth 
by methods involving only the vertical propagation of a horizontal shear wave.

It is not entirely rational to depend only on calculational methods to modify earthquake motions from some deep layer or bedrock to the surface. It would seem desirable to base inferences about site intensity modification on actual observations of surface motions as well as on calculations until such a time as measurements of motion become available from actual earthquakes at various depths beneath the surface for a number of different foundation conditions.

In spite of the fact that there is such uncertainty, it is possible to assign values to the parameters of importance in assessing site effects based on the general nature of differences in motions that appear reasonable, however.

\subsection{Vertical Motions}

Several recent statistical studies have been made of vertical and horizontal earthquake motions (Refs. 9 and 10). Although the scatter in results is quite great, it is our recommendation that the design motions in the vertical direction be taken as $2 / 3$ of the value in the horizontal direction across the entire frequency range. 
111. DESIGN SEISMIC LOADINGS

\subsection{Actual versus Effective Earthquake Motions}

Al though peak values of ground motion may be assigned to the various magnitudes of earthquake, especially in the vicinity of the surface expression of a fault or at the epicenter, these motions are in general considerably greater than smaller motions which occur many more times in an earthquake. Design earthquake response spectra are based on "effective" values of the acceleration, velocity and displacement, which occur several times during the earthquake, rather than isolated peak values of instrumental reading. The effective earthquake hazards selected for determining design spectra may be as little as one-half the expected isolated peak instrument readings for near earthquakes, ranging up to the latter values for distant earthquakes.

Design response spectra determined from these parameters can take into account the various energy absorption mechanisms, both in the ground and in the element, including radiation of energy into the ground from the responding system.

In the design of any system to resist seismic excitation, as discussed earlier herein, there are a number of parameters and design considerations that must be taken into account. Among these are the magnitude of the earthquake for which the design is to be made, the distance of the facility from the focus or fault, the parameters governing attenuation of motions with distance from the focus or epicenter, the soil or rock conditions as well as the general geologic conditions in the vicinity, and the parameters governing the response of the facility or 
the structure itself. Most, if not all, of these parameters are subject to considerable uncertainty in their value. Because so many of the parameters involved have probabilistic (rather than deterministic) distributions, it is not proper to take each of them with a high degree of conservatism because the resulting combined degree of conservatism would then be unreasonable. At the same time it is desirable to have an assured margin of safety in the combined design conditions. Hence, a choice must be made as to the parameters which will be taken with large margins of safety and those which will be taken with more reasonable values closer to the mean or expected values of the parameters.

The relation between magnitude of energy release in an earthquake and the maximum ground motion is very complex. There are some reasons for inferring that the maximum accelerations are, for example, nearly the same for all magnitudes of relatively shallow earthquakes for points near the focus or epicenter. However, for larger magnitudes, the values do not drop off so rapidly with distance from the epicenter, and the duration of shaking is longer. Consequently, the statistical mean or expected values of ground motions show a relationship increasing with magnitude, although not in a linear manner.

\subsection{Design Seismic Motion}

In selecting the earthquake hazards for use in design or review, the general concept used for the DBE, as discussed earlier, is that the earthquake magnitude selected should be at least as large as those that have occurred in the past, and these earthquakes are generally considered to have equal probabilities of occurring at any point within regions of similar or closely related geologic character. In particular, the 
estimates of motion considered are those appropriate for competent materials at or near the ground surface, including rock or competent consolidated sediments at or near the surface. It is fairly well recognized now that the predominant part of strong earthquake ground motion generated by a near shallow earthquake energy release, is represented by surface waves. In general, these are propagated in a manner consistent with the properties of the material at a depth considerably beneath the surface and are not affected to a large extent by the surface properties themselves. The design values of motion normally are based on the assumption that the same values are applicable in a particular zone for all competent soils. In summary, the maximum ground motion values to be used for review and upgrading may be considerably less than the isolated peak values of motion (as measured by instruments) that correspond to the magnitudes of earthquakes that might be assigned to the zones. 


\section{SOIL-STRUCTURE INTERACTION}

When a structure is founded within or on a base of soil and/or rock, it interacts with its foundation. The forces transmitted to the structure and the feedback to the foundation are complex in nature, and modify the free-field motions. Methods for dealing with soil-structure interaction have been proposed by a number of writers. These methods involve: (1) procedures similar to those applicable to a rigid block on an elastic half space; (2) finite element or finite difference procedures corresponding to various forcing functions acting on the combined structuresoil complex; (3) substructure modelling techniques which may or may not include use of the direct finite element method. Summaries of some of the factors and uncertainties affecting these calculations are given in Refs. 11 through 15. More advanced techniques are under development at a number of institutions, but all methods have yet to be tested and therefore conservative interpretation of the results of analysis is required.

However one makes the calculation, one determines a fundamental frequency and higher frequencies of the soil system which interacts with the structure, and effective damping parameters for the soil system taking into account radiation and material damping. Both of these quantities are necessary in order to obtain rational results. Procedures that emphasize one but not the other cannot give a proper type of interaction.

In general, consideration must be given to the influence of local soil and geologic conditions as affecting the site ground motions, both in terms of intensity and frequency content. Soft soil conditions, for example, may preclude the development of high accelerations or 
velocities within the foundation materials. Consideration must also be given to the development of unstable conditions such as soil liquefaction, slope instability, or excessive settlements. Further, because of the nature of formation of soil deposits and their lack of uniformity in some situations, in order to carry out meaningful calculations it may be desirable to consider the determination of in-situ properties; in such cases the methods of sampling and testing used to infer these properties need careful consideration. Because of the variations in properties and the difficulty of determining them accurately, some degree of variation in the basic parameters used in the calculations should be taken into account.

Finally, the method of calculation used should avoid as much as possible the introduction of spurious results arising from the calculational technique. For example, it is often necessary to avoid "reflecting" or "hard" boundaries where these do not actually exist.

This entire topic is one that requires the most careful consideration, and additional research and study over the next decade probably will be necessary before definitive recommendations on soil-structure interaction can be developed. In the interim for review and upgrading, it is recommended that great care be taken in assessing the need for such analyses. Careful judgment as to the meaning of the results, in the light of the comments given herein, is required. Reliance on any single method is to be avoided. 


\section{DAMPING AND ENERGY ABSORPTION}

\subsection{Implications of Damage or Collapse}

In considering the response of a structure to seismic motions, one must take account of the implications of various levels of damage, short of collapse, of the structure. Some elements of nuclear power plants must remain elastic or nearly elastic in order to perform their allocated safety function. In many instances, however, a purely linear elastic analysis may be unreasonably conservative when one considers that, even up to the near yield point range, there are nonlinearities of sufficient amount to reduce required design force levels considerably. This is discussed in more detail later herein in Section 7 dealing with review and retrofit design procedures.

A discussion of the design requirements for various items of nuclear power plants wherein nonlinear behavior is permitted, is given in Ref. 16, in the tabulation of design classes in that reference. Similar considerations are given in Ref. 17, pertaining to the Trans-Alaska $0 i 1$ Pipeline, where seismic design classes are used in defining the requirements to resist damage for the various elements of that system. An application of these concepts to nuclear reactor design is given in detail later in this report.

\subsection{Damping}

Energy absorption in the 1 inear range of response of structures to dynamic loading is due primarily to damping. For convenience in analysis, the damping is generally assumed to be viscous in nature (velocity dependent) and is so approximated. Damping levels have been determined from observation 
and ineasurement but show a fairly wide spread. For conservatism, damping values for use in design of nuclear plant systems are generally taken at lower levels than the mean or average estimated values.

Damping is usually considered as a proportion or percentage of the critical damping value, which is defined as that damping in a system which would prevent oscillation for an initial disturbance not continuing through the motion. Levels of damping, as summarized from a variety of sources, are given in Refs. 18-20. For convenience, the damping associated with particular structural types and materials as modified slightly from Ref. 21 is given herein in Table 1. The lower levels of the pair of values given for each item are considered to be nearly lower bounds, and are therefore highly conservative; the upper levels are considered to be average or slightly above average values, and probably are the values that should be used in design when moderately conservative estimates are made of the other parameters entering into the design criteria. A recent detailed study of damping has been completed as a part of the Diablo Canyon Units 1 and 2 Review (Amendment 50) and should be considered along with other data when setting up review criteria.

\subsection{Ductility}

Energy absorption in the inelastic range is commonly handled through use of the so-called "ductility factor". The ductility factor is the ratio of the maximum useful (or design) displacement of a structure to the "effective" elastic limit displacement, the latter being determined not from the actual resistance-displacement curve but from an equivalent elastoplastic function. This equivalence requires that the energy absorbed in 
the structure (or area under the resistance-displacement curve) at the effective elastic limit and at the maximum useful displacement must be the same for the effective curve as for the actual relationship at these two displacements. For the system shown in Fig. 1, the definition of the ductility factor, $\mu$, is shown in Fig. 2 .

Ductility levels for use in normal design may range from as low as 1.0 to 1.3 , or nearly elastic, to more than 5 , when a great deal of energy can be absorbed in inelastic deformation. It is expected that similar values should be applicable in the review design process.

Ductility levels for use in design are discussed in detail in Refs. 16 and 17, and in cosiderable detail in Section 7 of this report. 


\section{METHODS OF DYNAMIC ANALYSIS}

\subsection{Response Spectrum}

The concepts of the response spectrum and its use in dynamic analysis are discussed in detail in many books and articles, including Refs. 17 through 20, and 22. The response spectrum is defined as a graphical relationship of maximum response of a single-degree-of-freedom elastic system with damping to dynamic motion (or forces). The most usual measures of response are maximum displacement, $D$, which is a measure of the strain in the spring element of the system, maximum pseudo relative velocity, $V$, which is a measure of the energy absorption in the spring of the system, and maximum pseudo acceleration, $A$, which is a measure of the maximum force in the spring of the system. Although actual response spectra for earthquake motions are quite irregular, they have the general shape of a trapezoid or tent: a simplified spectrum is shown in Fig. 3, plotted on a logarithmic tripartite graph, and modified so that the various regions of the spectrum are smoothed to straight line portions. On the same graph are shown the maximum ground motion components, and the figure therefore indicates the amplifications of maximum ground motions for the various parts of the spectrum.

At any frequency, $f$, the relations between the values of $D_{f}, V_{f}$, and $A_{f}$ are defined as follows:

$$
\begin{aligned}
& v_{f}=\omega D_{f} \\
& A_{f}=\omega v_{f}=\omega^{2} D_{f}
\end{aligned}
$$

where $\omega$ is the circular natural frequency, $2 \pi f$. 
Let us now consider the case in which the simple oscillator of Fig. I deforms inelastically as in Fig. 2. It is convenient to use an elasto-plastic resistance displacement relation because one can draw response spectra for such a relation in generally the same way as spectra are drawn for elastic conditions. In Fig. 4 there are shown the two types of spectra corresponding to the elastic spectrum of Fig. 3 . Here the symbols D, V, A refer to the bounds of the elastic spectrum, the symbols $D^{\prime}, V^{\prime}, A^{\prime}$ to the bounds of the elasto-plastic spectrum for acceleration, and the symbols $D, V, A^{\prime \prime}, A_{O}^{\prime}$ to the bounds for the elasto-plastic spectrum for displacement. The symbol $A_{0}$ refers to the maximum ground acceleration. The method of constructing the inelastic spectra is described later in this report.

\subsection{Use of Response Spectra for Multi-Degree-of-Freedom Systems -- Model Analysis}

For multi-degree-of-freedom systems, the concept of the response spectrum can also be used in most cases, although the use of the inelastic response spectrum is only approximately valid as a design procedure. For a system with a number of masses at nodes in a flexible framework, the equation of motion can be written in matrix form as follows:

$$
M \ddot{u}+C \ddot{u}+K u=-M(\ddot{y})\{1\}
$$

where the quality in brackets represents a unit vector. The mass matrix $M$ is usually diagonal, but in all cases both $M$ and the stiffness matrix $K$ are symmetrical. When the damping matrix $C$ satisfies certain conditions, the simplest of which is when it is a linear combination of $M$ and $K$, then the systems has normal modes of vibration, with modal displacement vectors $u_{n}$ 
When the modes and frequencies of the system are obtained, the modal responses are determined for each mode considering the "participation" factors, $c_{n}$, for each mode to be defined as follows:

$$
c_{n}=\frac{u_{n}^{\top} M\{1\}}{u_{n}^{\top} M u_{n}}
$$

If the particular quantity desired -- say the stress at a particular point, the relative displacement between two reference points, or any other effect -- is designated by $\alpha$, then the modal values of $\alpha_{n}$ are determined for each mode and combined by use of the relations:

$$
\begin{aligned}
\alpha_{\max } & \leq \sum_{n}\left|c_{n} \alpha_{n} D_{n}\right| \\
\alpha_{\text {prob }} & \cong \sqrt{\sum_{n}\left(c_{n} \alpha_{n} D_{n}\right)^{2}}
\end{aligned}
$$

For inelastic response, the quantities to be used are $D_{n}^{\prime}, V_{n}^{\prime}$, or $A_{n}^{\prime}$ from calculations such as those leading to Fig. 4. Equation (7) gives an upper bound to the value of $\alpha$, and Eq. (8) the most probable or expected value.

\subsection{Time History Analysis}

Alternatively one may make a calculation of response by considering the motions to be applied and the responses computed using a step-by-step numerical dynamic analysis. This implies a deterministic approach since a deterministic time history is involved. By use of several time histories independently considered, one can arrive at average or conservative upper bounds of response, at the expense of a considerably increased amount of 
calculation. In general, however, there is no real advantage in using a time history as compared with a response spectrum approach for multi-degreeof-freedom systems, unless one is faced with an actual deterministic input. Another form of time history analysis sometimes employed involves modal analysis concepts in the sense of identifying the eigenvectors and eigenvalues, exciting each of the significant modes by the time history and summing the weighted modal values of stress, displacement, etc. as a function of time. This method is cumbersome, obviously must make use of a computer because of the extensive calculations required, and is not used widely.

It has been common to use time history analysis techniques to generate floor response spectra, especially at upper floor locations in nuclear power plants. Techniques currently exist for estimating the peak values of response at such locations (Ref. 23) and additional research studies currently underway at the University of 111 inois are intended to lead to improved techniques for estimating floor response spectra by employing modal analysis with response spectrum techniques. In any case the handling of floor response at multiple attachment locations, by whatever technique, is extremely difficult and requires exercise of judgment; in such cases one principal concern is that of adequately providing for relative displacement. 


\section{REVIEW ANALYSIS AND DESIGN PROCEDURES}

\subsection{General Considerations}

In undertaking review seismic analyses of an existing nuclear plant, preparatory to carrying out upgrade design studies, it is assumed that the general approach outlined in Section 1 of this report would be followed. As a part of the review process it is important to ascertain the nominal properties of the materials in the elements under consideration; in some cases it may be necessary to carry out tests to determine these properties, especially if aging, corrosion or other effects could have affected the properties.

The load combinations that should be considered in the review should be those for which the upgrade is to be made, and should include consideration of current Nuclear Regulatory Commission guidelines. In other respects it is assumed that the general loadings and safety provisions of the current NRC standards would apply within the framework of the procedures and criteria given in this report.

\subsection{Modified Response Spectra}

Modified response spectra representing average (or some probability above the mean) conditions for earthquake motions are discussed in various books and papers, including Refs. 16-23. In general it.has been shown that a response spectrum for a particular cumulative probability level can be derived from statistical studies of actual earthquakes, most conveniently as a set of amplification factors applied to the maximum components of ground motion, as implied in Fig. 3. The probability function which best describes the range of values is one that corresponds to a logarithmic 
normal distribution. The amplification factors are functions of damping. Equations for the amplification factors for the log normal distribution, for both the median or 50 percentile cumulative probability level and the one Sigma or 84.1 percent cumulative probability level, are shown in Table 2. Specific numerical values for a range of damping values from 0.5 percent critical to 20 percent critical for the two probability levels are tabulated separately in Table 3 for acceleration, velocity, and displacement sensitive regions of the response spectrum as shown in Fig. 3 .

In determining the ground motions for use with Fig. 3 , it is recommended that, lacking other information, for competent soil conditions a v/a ratio of $48 \mathrm{in} / \mathrm{sec} / \mathrm{g}$ be used and for rock a v/a ratio of $36 \mathrm{in} / \mathrm{sec} / \mathrm{g}$ be used. Also to ensure that the spectrum represents an adequate band (frequency) width to accommodate a possible range of earthquakes it is recommended that $a d / v^{2}$ be taken equal to about 6.0 . In the above $a, v$ and $d$ are the maximum values of ground motion (acceleration (in/ $\sec ^{2}$ ), velocity (in/sec), and displacement (in), respectively).

With these values one can determine for a given earthquake the smoothed elastic response spectrum for a particular value of damping and a given probability level.

\subsection{Effects of Size and Weight of Structure}

There is a good basis for recognizing that a large and heavy structure responds to motions in the soil or rock supporting it in a manner different from that of a light and small support for a recording accelerometer. Crude analytical studies suggest that high frequency 
motions are not transmitted as effectively to the foundation of a structure, and therefore to the structure itself, as lower frequency motions. This may be ascribed to several factors, the most important of which are probably the facts that: (1) the earthquake motion is a wave motion, the higher frequency components of which may be shorter than the length or width of the responding structure; and (2) there is a loss of energy in the high frequency range, not accounted for in the analysis, that comes from possible relative motions between the base and the foundation. These observations are corroborated by the response of the Hollywood Parking Lot and the Hollywood Storage Building in Los Angeles, which are adjacent to one another, in which in the first case the instrument is mounted in the so-called "free field" and the other in the basement of the structure. The Response Spectra and the Fourier Spectra are practically identical for frequencies lower than about 1 to 2 hertz, but differ markedly, by as much as a factor of 2 to 3 , for frequencies higher than about 3 to 4 hertz.

For these reasons, it is considered that high intensity earthquake motions, and especially those arising from near field sources, have much less influence on structural response and damage produced by this response than do earthquakes having a more distant source, where the major motions are in frequency ranges to which the structure can respond effectively as a unit. This is a justification that is often used for discounting high intensities of acceleration that are measured or inferred, as compared with those used in the development of design spectra. It is our belief that this type of soil-structure interaction should be taken into account in arriving at design spectra for facilities with large foundations, as for example nuclear plants. Procedures for making such modifications are 
available in the literature (for example, Refs. 24 and 25 ).

\subsection{Effects of Inelastic Action}

The effects on the response of a structure deforming into the inelastic range have been described and/or summarized in Refs. 16 through 22 . In general, for small excursions into the inelastic range, when the latter is considered to be approximated by an elasto-plastic resistance curve, the response spectrum is decreased generally by a factor which is one over the ductility factor. If the ductility factor is defined by the symbol $\mu$ then the reduction for the two left-hand portions of the elastic response spectrum shown in Figs. 3 and 4 (to the left of the frequency of about 2 hertz) is reduced by the factor $1 / \mu$ for acceleration, and by the factor of $1 / \sqrt{2 \mu-T}$ in the constant acceleration portion to the right, roughly between frequencies of 2 and 8 hertz. There is no reduction beyond about 33 hertz. With this concept, one can arrive at design spectra that take account of inelastic action even in the small range of inelastic behavior.

\subsection{Seismic Design Classification}

Because of the major influence that the ductility factor has on the design spectrum, some guidance is needed with regard to the appropriate choice of ductility factors to be used even for vital elements and components in a nuclear reactor facility. Observations of the performance of structures in earthquakes, interpretation of laboratory tests, including those on earthquake simulators and shake tables, observations of damage to structures 
and structural models in nuclear tests, including damage both from air blast and ground shock, as well as system safety, all are pertinent factors in arriving at a judgment as to the appropriate ductility factor to be used in review analyses and upgrade design.

In order to provide guidance, taking into account the factors described above, a seismic design classification is suggested in Table 4. It involves a designation of the seismic design class and a description of those items that should be assigned to that class. For each class, a range of ductility factors is given. Obviously appropriate damping values also must be chosen for use in evaluating the seismic adequacy of the systems under study. It is believed that even the upper limit of the range shown in Table 4 would be adequately conservative for all items in the class, but one may choose, for greater conservatism, to use a lower value. Classes 1-S, 1 , and II might be considered as applicable to various types of nuclear reactor elements, components, or facilities; Class 111 would generally be considered to fall into the range of ordinary structures which can be designed by current or proposed somewhat modified seismic design specifications and codes used for buildings.

\subsection{Design Spectra}

Using the concepts described above, the design spectrum for earthquake motions can be drawn as shown herein in Fig. 4 generally. The response spectrum indicated by the line $D V A A_{0}$ in Fig. 4 is the elastic response spectrum obtained from Fig. 3, using the probability levels, damping values and amplification factors, appropriate to the particular excitation and structural component. From this, by use of the ductility 
reductions described in Section 7.5 , one obtains the design spectrum for acceleration or force by the curve $D^{\prime} V^{\prime} A^{\prime} A_{0}$, and for displacement by the curve DVA'A', which represents the total displacement and not the elastic component of displacement, for the elasto-plastic resistance curve. A specific example of the design spectrum which includes all of the quantities described in the report, for a peak ground acceleration of about $0.16 \mathrm{~g}$, 5 percent of critical damping and a ductility factor of 3 is presented in Fig. 5 .

\subsection{Combined Effects of Horizontal and Vertical Excitation}

In the real world, earthquake motions occur as random motions in horizontal and vertical directions. In other words, a structure is subjected to components of motion in each of two perpendicular horizontal directions and the vertical direction, and one might also consider three components of rotational motion corresponding to a foundation twist about a vertical axis and two rocking motions about the horizontal axes. These ground motions have, apparently, statistical independence. Consequently, if one uses time histories of motion one must either. use actual earthquake records or modify them in such a way as to maintain the same degree of nearly statistical independence as in actual records. Consequently, for time histories that involve inelastic behavior, it is an oversimplification to consider each of the components of motion independently since they all occur at the same time in general. However, there is only a small probability of the maximum responses occurring simultaneously and methods have been derived for handling problems such as this as described next.

For design one must consider the combined effects of motion in various directions. Although this can be done in various ways depending 
upon the method of analysis used, it is reasonable to use the response spectrum approach even for the multi-degree-of-freedom systems, to arrive separately at the responses in the individual directions, and then to combine the effects in general by taking the square root of the sums of the squares of the individual effects for stress or motion at a particular point in a particular direction for the various components of motion considered. It is conservative, simpler, and much more readily defined and calculated to take the combined effects as 100 percent of the effects due to motion in one particular direction and 40 percent of the effects corresponding to the two directions of motion at right angles to the principal motion considered. It is this combination that is recommended for general use, especially in nuclear power plant design.

\subsection{Unsymmetrical Structures, Torsion, Overturning and Uplift}

Consideration should be given to the effects of torsion on unsymmetrical structures, and even on symmetrical structures where torsion may arise accidentally, because of various reasons, including lack of homogeneity of the structures, or the wave motions developed in earthquakes.

$$
\text { So-called "calculated" torsion in the structure proper arising }
$$

from noncoincident centers of mass and rigidity should be handled in the customary manner. The accidental eccentricities of the horizontal forces prescribed by current codes require that 5 percent of the width of the structure in the direction of the earthquake motion considered be used as an accidental eccentricity. The stresses arising from the actual eccentricity should be combined with those arising from the accidental eccentricity in all cases. The effect of eccentricity is to produce 
a greater stress on one side of the structure than on the other, and the outer walls and columns will in general be subjected to larger deformations and forces than would be the case if the structure were considered to deform uniformly.

Recently new techniques for estimating torsion arising from ground motion have been studied and reported in the literature (Ref. 25) but it is not clear at this moment that such treatment involving a systematic plane wave is justifiable; in some cases, especially in large buildings, it leads to values which are higher than appear reasonable. In the interim it is our recommendation that current code provisions for "accidental" torsion be employed.

In estimating overturning effects one commonly computes the shears and moments throughout the structure and computes the "overturning" moment at each elevation and at the base. These moment forces give rise to tensions and compressions in the columns and walls of the structure, and cause tilting of the base consistent with the foundation compliance. In some cases this tilting can lead to partial uplift on one edge of the base and can lead to overloading of the foundation materials.

\subsection{Response of Equipment and Attachments}

Many important parts of a nuclear power plant facility are attached to the principal parts of the structure and respond in a manner determined by the structural response rather than by the general ground motion to which the structure is subjected. This matter involves a good deal of difficulty in analysis, but appropriate calculational techniques are available. Some of 
these are described in Ref. 23 , where a suitable design simplification is involved in which the response of the attachment is related to the modal response of the structure. This response is affected by the relative mass of the attachment and the structure. Where this relative mass is infinitesimal, the response is affected primarily by the damping of the structure and the equipment, but as the relative mass becomes finite, even though small, an effective relative damping is involved which is related to the square root of the equipment to structure effective mass ratio.

The studies reported in Ref. 23 , and more recent unpublished research, indicate that in general the maximum response of a light equipment mass attached to a structure, even when the equipment mass is tuned to the same frequency as the structure, will not exceed the basic response spectrum to which the structure responds multiplied by an amplification factor, AF, defined conservatively as follows:

$$
A F=\frac{1}{\beta_{e}+\beta_{s}+\sqrt{\gamma}}
$$

in which

$\beta_{e}=$ proportion of critical damping for equipment

$\beta_{S}=$ proportion of critical damping for structure

$\gamma=$ ratio of generalized mass of equipment to generalized mass of structure, when the mode displacement vectors for both the equipment and structure are taken so as to have unit participation factors, defined by use of Eq. (6)

The generalized mass for the $n$th mode, $\bar{M}_{n}$, is defined for either the equipment or the structure as: 


$$
\bar{M}_{n}=u_{n}^{\top} M u_{n}
$$

in which $M$ is the mass matrix and $u_{n}$ the modal displacement vector (for either the equipment or the structure) normalized to a unit participation factor for either system alone.

It is to be noted that even a mass ratio for equipment to structure of 0.0001 corresponds to an equivalent added damping factor of 0.01 or 1 percent and a mass ratio of 0.001 to an added factor of about 3.2 percent. As described earlier in this report, a commonly employed technique for handling equipment response is that of the so-called floor-response or in-structure response spectrum. The use of this technique involves considerable judgment in assessing the reasonableness of the peak response values and the frequency bandwidth of applicability. Multiple connections are even more troublesome to handle, irrespective of the technique employed.

In any event, however the motions are estimated, the analyst or designer must pay particular attention to tie-down details and to connecting elements which can undergo or must sustain relative motion. 


\section{SPECIAL TOPICS}

\subsection{Fault Motions}

Major fault motions may occur in large magnitude earthquakes of the order of as much as 6 to 8 meters in relative motion between the two sides of the fault. Such motions are virtually impossible to design against. However, small fault motions or motions across subsidiary faults, or fault motions for small magnitude earthquakes, may range from a few centimeters to a meter or so. For these it is possible to provide resistance to the relative motions by some means of isolation of the structure. Some methods of doing this were described in Ref. 18. More recent studies and recommendations pertaining to pipelines and other buried facilities are given in Refs. 26 and 27 .

\subsection{Relative Motions}

Relative motions between different parts of a facility or between different elements in a strucrure often have to be considered in design. Because of the fact that elements and separate items may respond in such a way that, even though they have the same period of vibration and the same general response characteristics, they may become out of phase in their motions, the design relative motion generally has to be taken as the sum of the absolute values of the maximum motions of the two components involved. More details on this topic are contained in Ref. 23.

Another observation of interest in this connection is that for some elements undergoing restricted motion, as for example buried piping, it is possible under certain circumstances that the relative seismic motion stressing may be "secondary" in character as opposed to a "primary", with 
the terms "secondary" and "primary" referring to definitions as given in current codes. This matter deserves further study.

\subsection{Underground Conduits and Piping}

Important components of nuclear reactors often involve underground tunnels or other conduits and piping. In general these may have to deform in a manner consistent with the deformation or strains in the soil or rock medium itself, and do not respond in a way anticipated by the so-called response spectrum approach or other structural analysis approach. Methods of handling this problem are described in some detail in Refs. 23, 26 and 27 and have been used as design criteria for underground piping systems.

In that reference, based on the assumption that over short distances the earthquake motions propagate as a wave with a velocity of transmission $c$, it was shown that the maximum longitudinal strain $\varepsilon_{m}$ in a buried conduit or pipe, except near a surface break or fault, is given by the relations:

For "compression waves" in the ground

$$
\varepsilon_{m}=v_{m} / c_{p}
$$

and for "shear, waves"

$$
\varepsilon_{m}=v_{m} / 2 c_{s}
$$

in which

$$
\begin{aligned}
& v_{m}=\text { maximum ground velocity } \\
& c_{p}=\text { compression wave transmission velocity in medium } \\
& c_{s}=\text { shear wave transmission velocity in medium }
\end{aligned}
$$

However, the values of $c_{p}$ and $c_{s}$ should not be taken as the very small values 
that might occur near the surface in soft soil, because the wave transmission velocity is affected primarily by the stiffer deep strata.

The strains in a pipe due to changes in curvature in the ground are discussed in Refs. 23, 26 and 27. They are generally small enough to be neglected.

\subsection{Tanks and Vaults}

Analysis and design procedures for aboveground tanks and vaults have been based over the years primarily on the work by Housner, especially as summarized in Ref. 28. These procedures have provided a reasonably satisfactory basis for design over the years. More recently several major studies have been underway, particularly with reference to petroleum storage facilities; the studies noted are those involving experimental testing as well as analysis under the direction of $R$. Clough at the University of California at Berkeley and theoretical studies by A. S. Veletsos at Rice University in Houston. It is expected that these studies will lead to new guidelines for tank design in the near future. The anchorage requirements for tanks are now fairly standard and would need review as would connecting piping.

In the case of buried tanks or vaults the problems are slightly different in that the tanks will move and deform with the ground as a function of the compliance between the tank and ground. Again it is an interaction problem. To some degree but not entirely, the strain in a tank or vault can be inferred from the strains in the ground (See Section 8.3). of particular concern in review of existing plants would be tanks buried for some period of time where corrosion or other aging effects could degrade 
the properties of the tank materials with respect to their ability to withstand seismic motion without leaking.

\subsection{Equipment Qualification}

An important element of the review of existing nuclear facilities involve's the seismic adequacy of the critical controls and equipment. This is an area in which improved techniques and practices have been developed with regularity. It is conceivable that some of the items of equipment in the existing facility which were not evaluated during an earlier design era may indeed be of a type which has been evaluated in ensuing years and this information should be obtained if at all possible. In many cases based on recent testing and analysis experience it is possible to make judgments about the adequacy of certain types and classes of equipment. Insofar as possible it is recommended that the equipment qualification be carried out in accurdance with Standard 344-75 of IEEE and the accompanying standards which relate to general qualification requirements. In many cases it is conceivable that the equipment itself will have adequate resistance for the seismic hazard involved and that additional resistance of the system can be developed through the adding of additional anchorage, bracing or other remedial measures.

In the case of new equipment which is installed as a part of the redesign and upgrading, we call particular attention to a recent systematic program of equipment evaluation that was carried on for the trans-Alaska pipeline as described in detail in Ref. 31. This particular programi involved one of the most systematic and well documented studies of this type known to the authors. 


\subsection{Quality Control and Details of Construction}

Items which do not lend themselves readily to analytical consideration may have an important effect on the response of structures and facilities to earthquake motions and must be considered in the design. Among these items are such matters as the details and material properties of the elements and components, and the inspection and control of quality in the construction procedure. The details of connections of the structure to $i$ ts support or foundations, as well as of the various elements or items within the structure or component, are of major importance. Failures often occur at connections and joints because of inadequacy of these to carry the forces to which they are subjected under dynamic conditions. Inadequacies in properties of material can of ten be encountered, leading to brittle fracture where sufficient energy cannot be absorbed, even though energy absorption may have been counted on in the design and may be available under static loading conditions. Some of the aspects of these topics are considered in detail in Refs. 28 and 30 for reinforced concrete. Similar concepts must be followed, however, for other construction materials as well.

The review must include examination of details of construction, fastening, and actual material properties to be sure that the resistance available is adequate to meet the demands of the upgraded design requirements.

\subsection{Probability Concepts}

Although probability concepts are not generally used in the design of new reactors, it is likely that they can be used in considering the appropriate level of upgrading and retrofit to bring an older reactor to acceptable safety levels. However, studies are required to define acceptable 
levels of risk and structural or component resistance before risk analysis can be used as a sole basis for decision as to redesign or upgrading requirements. Such studies are underway now, both for seismic hazard and for dynamic response.

Use of probability concepts is almost necessary, however, to define appropriate levels of damping, energy absorption capability or ductility, and fragility levels of components and equipment, since selection of all these parameters at extreme or bounding values would lead to unreasonable, or almost irrational, seismic design requirements that would introduce dangers from overstiff and/or brittle behavior mechanisms that would be more serious in terms of safety considerations. 


\section{SUMMARY REVIEW AND REPORTING}

\subsection{Audit Procedure and Systems Summary}

As described in Section 1 of this report a major portion of the review and analysis procedure for an operating nuclear plant involves making an audit of the status of the existing equipment structures, elements, and other critical items. The audit should include many things, namely a listing of those items and systems considered critical, the documentation that exists with regard to them, and the methods used in the analysis of the items. Also it should include any factual details that exist with regard to the stress analysis, selection of support and resisting systems, and specifically any information that exists with regard to the amount of the stress and deformation which could be attributed to the seismic hazard for which the plant was designed. This latter item will provide some insight, even in the light of the methods of analysis used at the time, of the probable significance of the seismic effects upon the items of consideration.

A thorough and useful audit involves a large amount of time and painstaking effort but is an absolute necessity if documentation and justification of the existing facilities are required as a part of the upgrading procedure, which would be expected. 


\section{REFERENCES}

1. Donovan, N. C., "A Statistical Evaluation of Strong Motion Data Including the February 9, 1971 San Fernando Earthquake," Proceedings Fifth World Conference on Earthquake Engineering (Rome), Vol. 1, 1974, pp. 1252-1261.

2. Schnabel, P. B. and H. B. Seed, "Accelerations in Rock for Earthquake in the Western United States," Bulletin Seismological Society of America (USA), Vol. 63, No. 2, 1973, pp. 501-516.

3. Page, R. A., D. M. Boore, W. B. Joyner and H. W. Coulter, "Ground Motion Values for Use in the Seismic Design of the Trans-Alaskan Pipeline System," U.S.G.S. Survey Circular 672, 1972, 23 p.

4. Ambraseys, N. N., "Dynamics and Response of Foundation Materials in Epicentral Regions of Strong Earthquakes," Proceedings Fifth World Conference on Earthquake Engineering (Rome), Vol. 1, 1974, pp. CXXVICXLVIII.

5. Trifunac, M. D. and A. G. Brady, "On the Correlation of Seismic Intensity Scales for the Peaks of Recorded Strong Ground Motion," Bulletin Seismological Society of America (USA), Vol. 65, No. 1, 1975, pp. 139-162.

6. Seed, H. B., C. Ugas and J. Lysmer, "Site Dependent Spectra for EarthquakeResistant Design," Earthquake Engineering Research Center (Berkeley, California), Report No. EERC74-12, 1974, $17 \mathrm{p}$.

7. Mohraz, B., "A Study of Earthquake Response Spectra for Different Geological Conditions," Institute of Technology, Southern Methodist University (Dallas, Texas), 1975, $43 \mathrm{p}$.

8. Hanks, T. C., "Strong Ground Motion of the San Fernando, California, Earthquake: Ground Displacements," Bulletin Seismological Society of America (USA), Vol. 65, No. 1, 1975, Pp. 193-226.

9. Newmark, N. M., W. J. Hall and B. Mohraz, "A Study of Vertical and Horizontal Earthquake Spectra,". Directorate of Licensing, U.S. Atomic Energy Commission, Report WASH-1255, April 1973, 151 p.

10. Hall, W. J., B. Mohraz and N. M. Newmark, "Statistical. Studies of Vertical and Horizontal Earthquake Spectra," prepared for U.S. Nuclear Regulatory Commission, Report NUREG-0003, Jan. 1976, 128 p.

11. Idriss,. I. M., Chairman, "Analyses for Soil-Structure Interaction Effects for Nuclear Power Plants," Report by Ad Hoc Group on Soil-Structure Interaction, Structural Division, American Society of Civil Engineers, Draft, 5 December 1975.

12. E. D'Appolonia Consulting Engineers, Inc., "Soil-Structure Interation for Nuclear Power Plants," Report DAP-TOP I, May 1975. 
13. Newmark, N. M., A. R. Robinson, A.H.-S. Ang, L. A. Lopez and W. J. Hall, "Methods for Determining Site Characteristics," Proceedings International Conference on Microzonation, NSF-UNESCO-University of Washington-ASCEAcad. Mechs. (Seattle, Washington), Vol. 1, 1972, pp. 113-129.

14. Chopra, A. K., "Inter-Relationship of Methods for Earthquake Analysis of Structure-Soil Interaction," in Advances in Civil Engineering through Engineering Mechanics, ASCE, 1977, Pp. 36-39.

15. "Recommended Comprehensive Seismic Design Provisions for Buildings," prepared by the Applied Technology Committee, 480 Calif. Ave., Suite 205, Palo Alto, Calif. 94306, available in late 1977.

16. Newmark, N. M., "A Response Spectrum Approach for Inelastic Seismic Design of Nuclear Reactor Facilities," Transactions Third International Conference on Structural Mechanics in Reactor Technology (London), Paper K5/1, 1975.

17. Newmark, N. M., "Seismic Design Criteria for Structures and Facilities, Trans-Alaska Pipeline System," Proceedings U.S. National Conference on Earthquake Engineering (Ann Arbor, Michigan), Earthquake Engineering Research Institute, June 1975, pp. 94-103.

18. Newmark, N. M., "Design Criteria for Nuclear Reactors subjected to Earthquake Hazards," Proceedings of the IAEA Panel on Aseismic Design and Testing of Nuclear Facilities, the Japan Earthquake Promotion Society (Tokyo), 1969, pp. 90-113.

19. Newmark, N. M. and W. J. Hall, "Seismic Design Criteria for Nuclear Reactor Facilities," Proceedings Fourth World Conference on Earthquake Engineering (Santiago, Chile), Vol. 11, 1969, pp. B4-37-84-50.

20. Newmark, N. M., J. A. Blume and K. K. Kapur, "Seismic Design Spectra for Nuclear Power Plants," Journal Power Division, ASCE (New York), Proceedings, Vol. 99, No. P02, Nov. 1973, pp. 287-303.

21. Newmark, N. M. and W. J. Hall, "Procedures and Criteria for Earthquake Resistant Design," Building Practices for Disaster Mitigation, National Bureau of Standards (Washington, D.C.), Building Science Series 46, Vol. 1, Feb. 1973, pp. 209-236.

22. Newmark, N. M. and E. Rosenblueth, Fundamentals of Earthquake Engineering, Prentice-Hall, Inc. (Englewood Cliffs, N.J.), 1971, 640 p.

23. Newmark, N. M., "Earthquake Response Analysis of Reactor Structures," Nuclear Engineering and Design (The Netherlands), Vol. 20, No. 2, July 1972, pp. 303-322.

24. Newmark, N. M., W. J. Hall and J. R. Morgan, "Comparison of Building Response and Free Field Motion in Earthquakes, "Proceedings 6th World Conference on Earthquake Engineering, 1977, 6 p. (in press) 
25. Whitley, J. R., J. R. Morgan, W. J. Hall and N. M. Newmark, "Base Response Arising from Free-Field Motions," Transactions 4th SMiRT Conference, Paper K2/15, Vol. K(a), 1977, 10 p.

26. Newmark, N. M. and W. J. Hall, "Pipeline Design to Resist Large Fault Displacement," Proceedings U.S. National Conference on Earthquake Engineering, EERI, 1975, pp. 416-425.

27. Hall, W. J. and N. M. Newmark, "Seismic Design Criteria for Pipelines and Facilities," Proceedings Lifeline Earthquake Engineering Specialty Conference, ASCE, 1977, pp. 18-34.

28. "Nuclear Reactors and Earthquakes," Report TID 7024, prepared by Holmes and Narver for US AEC, 1963.

29. Blume, J. A., N. M. Newmark and L. Corning, Design of Multi-Story Reinforced Concrete Buildings for Earthquake Motions, Portland Cement Association (Chicago), 1961, $350 \mathrm{p}$.

30. Newmark, N. M. and W. J. Hall, "Dynamic Behavior of Reinforced and Prestressed Concrete Buildings under Horizontal Forces and the Design of Joints (including Wind, Earthquake Blast Effects), "Preliminary Publication, 8th Congress, International Association for Bridge and Structural Engineering (New York), September 1968, pp. 585-613; French translation pp. 614-638; German translation pp 639-661.

31. Anderson, T. L. and D. J. Nyman, "Lifeline Earthquake Engineering for the Trans-Alaska Pipeline System," Proceedings Lifeline Earthquake Engineering Specialty Conference, ASCE, 1977, Pp. 35-49. 
TABLE 1. RECOMMENDED DAMPING VALUES

\begin{tabular}{|c|c|c|}
\hline Stress Level & $\begin{array}{l}\text { Type and Condition } \\
\text { of Structure }\end{array}$ & $\begin{array}{l}\text { Percentage } \\
\text { Critical Damping }\end{array}$ \\
\hline \multirow[t]{3}{*}{$\begin{array}{l}\text { Working stress, } \\
\text { no more than about } \\
\frac{1}{2} \text { yield point }\end{array}$} & $\begin{array}{l}\text { a. Vital plping } \\
\text { b. Welded steel, prestressed } \\
\text { concrete, weil reinforced concrete } \\
\text { (only slight cracking) }\end{array}$ & $\begin{array}{l}1 \text { to } 2 \\
2 \text { to } 3\end{array}$ \\
\hline & $\begin{array}{l}\text { c. Reinforced concrete with } \\
\text { considerable cracking }\end{array}$ & 3 to 5 \\
\hline & $\begin{array}{l}\text { d. Bolted and/or riveted steel, } \\
\text { wood structures with nalled or } \\
\text { bol ted joints }\end{array}$ & 5 to 7 \\
\hline \multirow{6}{*}{$\begin{array}{l}\text { At or just below } \\
\text { yield point }\end{array}$} & a. Vital piping & 2 to 3 \\
\hline & $\begin{array}{l}\text { b. Welded steel, prestressed concrete } \\
\text { (w/thout complete loss in prestress) }\end{array}$ & 5 to 7 \\
\hline & $\begin{array}{l}\text { c. Prestressed concrete wl th no } \\
\text { prestress left }\end{array}$ & 7 to 10 \\
\hline & d. Reinforced concrete & 7 to 10 \\
\hline & $\begin{array}{l}\text { e. Bolted and/or riveted steel, wood } \\
\text { structures, with bol ted joints }\end{array}$ & 10 to 15 \\
\hline & f. Wood structures with nalled joints & 15 to 20 \\
\hline
\end{tabular}


TABLE 2. EQUATIONS FOR SPECTRUM AMPLIFICATION FACTORS FOR HORIZONTAL MOTION

\begin{tabular}{|c|c|c|}
\hline Quantity & $\begin{array}{c}\text { Cumulative } \\
\text { Probabllity, } \%\end{array}$ & Equation \\
\hline $\begin{array}{l}\text { Acceleration } \\
\text { Velocity } \\
\text { Displacement }\end{array}$ & 84. I (One Sigma) & $\begin{array}{l}4.38-1.04 \ln \beta \\
3.38-0.67 \ln \beta \\
2.73-0.45 \ln \beta\end{array}$ \\
\hline $\begin{array}{l}\text { Acceleration } \\
\text { Velocity } \\
\text { Displacement }\end{array}$ & 50 (Median) & $\begin{array}{l}3.21-0.68 \ln \beta \\
2.31-0.41 \ln \beta \\
1.82-0.27 \ln \beta\end{array}$ \\
\hline
\end{tabular}

TABLE 3: SPECTRUM AMPLIFICATION FACTORS FOR HORIZONTAL ELASTIC RESPONSE

\begin{tabular}{|c|c|c|c|c|c|c|}
\hline \multirow{2}{*}{$\begin{array}{l}\text { Damping, } \\
\% \text { Critical }\end{array}$} & \multicolumn{3}{|c|}{ One Sigma $(84.1 \%)$} & \multicolumn{3}{|c|}{ Median $(50 \%)$} \\
\hline & A & v & D & A & v & D \\
\hline $\begin{array}{c}0.5 \\
1 \\
2 \\
3 \\
5 \\
7 \\
10 \\
20\end{array}$ & $\begin{array}{l}5.10 \\
4.38 \\
3.66 \\
3.24 \\
2.71 \\
2.36 \\
1.99 \\
1.26\end{array}$ & $\begin{array}{l}3.84 \\
3.38 \\
2.92 \\
2.64 \\
2.30 \\
2.08 \\
1.84 \\
1.37\end{array}$ & $\begin{array}{l}3.04 \\
2.73 \\
2.42 \\
2.24 \\
2.01 \\
1.85 \\
1.69 \\
1.38\end{array}$ & $\begin{array}{l}3.68 \\
3.21 \\
2.74 \\
2.46 \\
2.12 \\
1.89 \\
1.64 \\
1.17\end{array}$ & $\begin{array}{l}2.59 \\
2.31 \\
2.03 \\
1.86 \\
1.65 \\
1.51 \\
1.37 \\
1.08\end{array}$ & $\begin{array}{l}2.01 \\
1.82 \\
1.63 \\
1.52 \\
1.39 \\
1.29 \\
1.20 \\
1.01\end{array}$ \\
\hline
\end{tabular}


TABLE 4. PROPOSED SEISMIC DESIGN CLASSIFICATION

CLASS

DESCRIPTION

I-S Equipment, instruments, or components performing vital functions that must remain operative during and after earthquakes;

Structures that must remain elastic or nearly elastic;

Facilities performing a vital safety-related function that must remain functional without repair. Ductillty factor $=1$ to 1.3 .

I Items that must remain operative after an earthquake but need not operate during the event; Structures that can deform slightly in the inelastic range; Facilities that are vital but whose service can be interrupted until minor repairs are made. Ductility factor $=1.3$ to 2 .

II

Facilities, structures, equipment, instruments, or components that can deform inelastically to a moderate extent without unacceptable loss of function; Structures housing items of Class I or I-S that must riot be permitted to cause damage to such items by excessive deformation of the structure. Ductility factor $=2$ to 3 .

III All other items which are usually governed by ordinary seismic design codes; Structures requiring seismic resistance in order to be repalrable after an earthquake. Ductllity factor $=3$ to 8 , depending on material, type of construction, design of details, and control of quallty. 


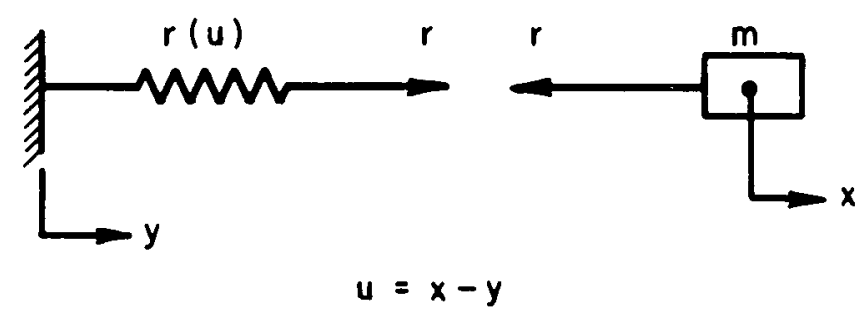

FIG, I SIMPLE UNDAMPED MASS-SPRING SYSTEM

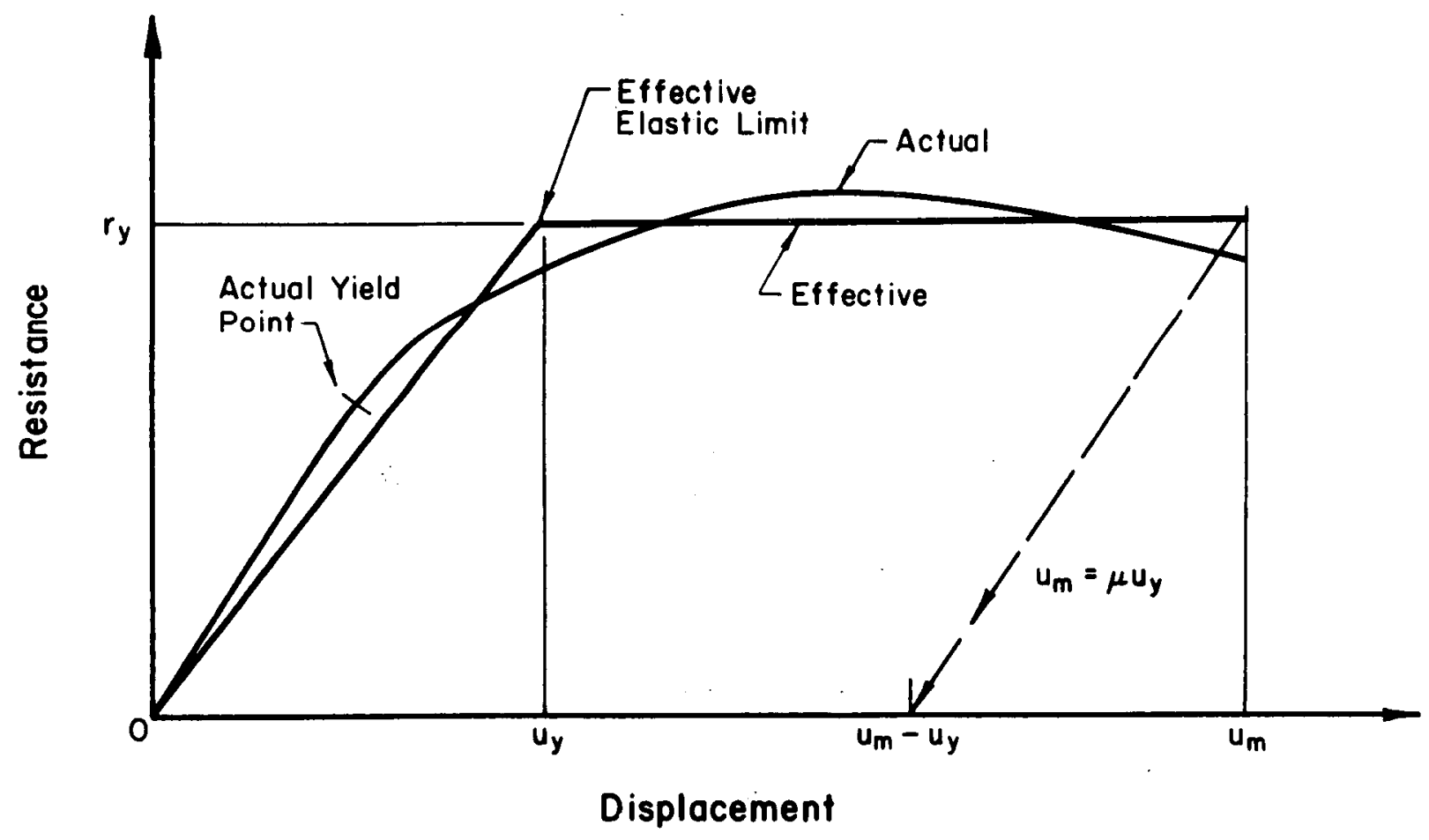

FIG. 2 RESISTANCE - DISPLACEMENT RELATIONSHIP 
48

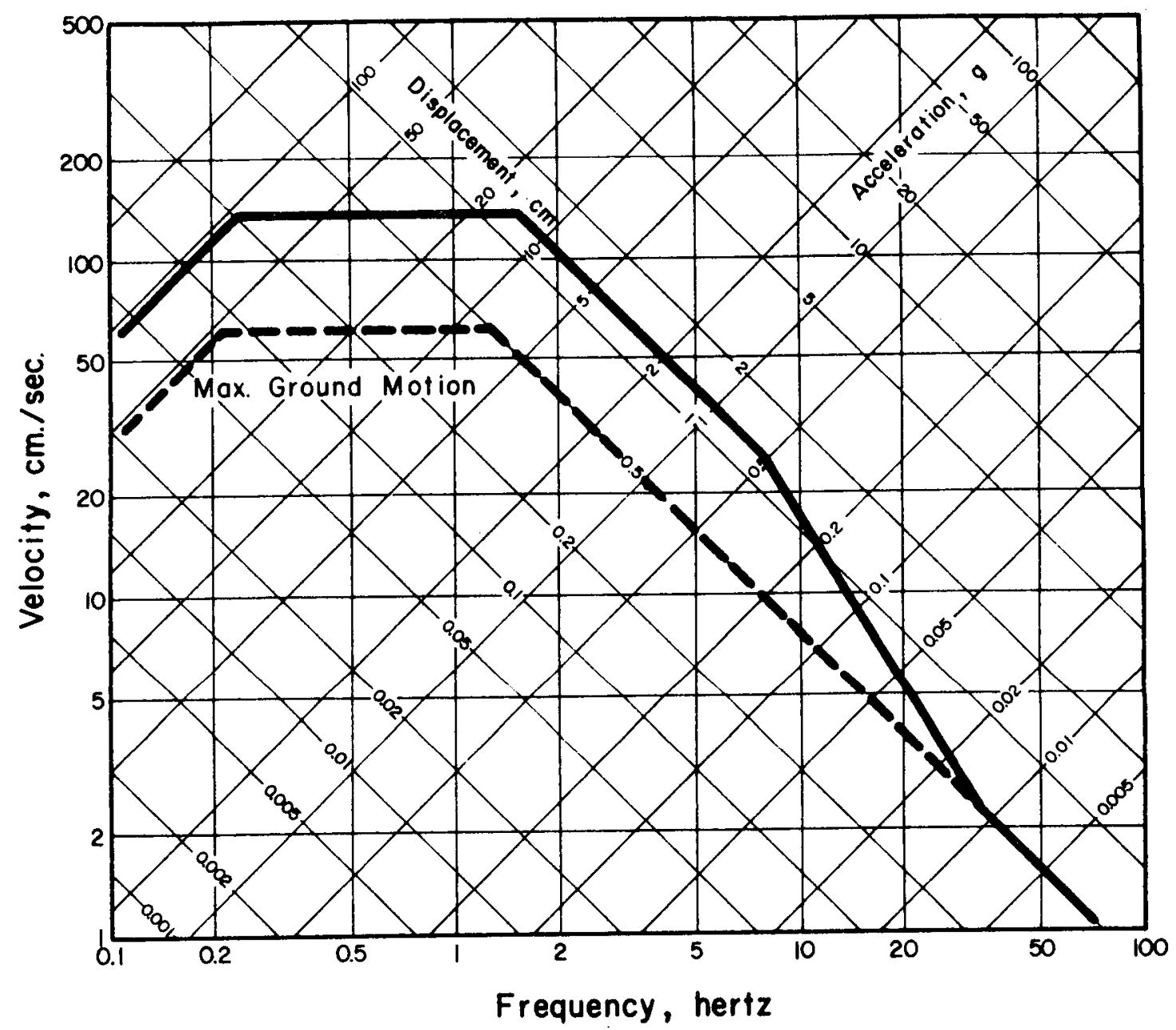

FIG. 3 ELASTIC DESIGN SPECTRUM, HORIZ. MOTION, (0.5 g MAX. ACCEL., $5 \%$ DAMPING, ONE SIGMA CUM. PROBABILITY)

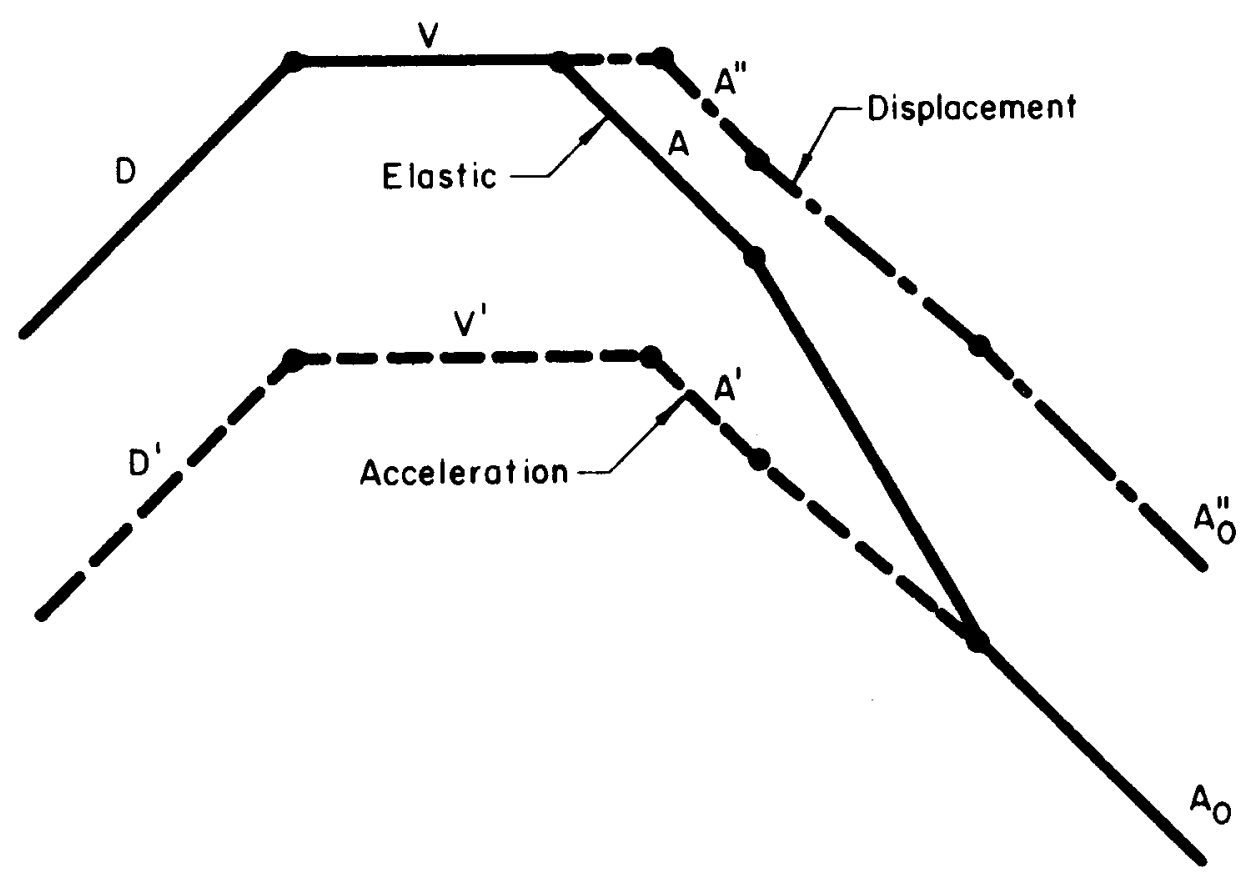

FIG. 4 DESIGN SPECTRA FOR EARTHQUAKES 


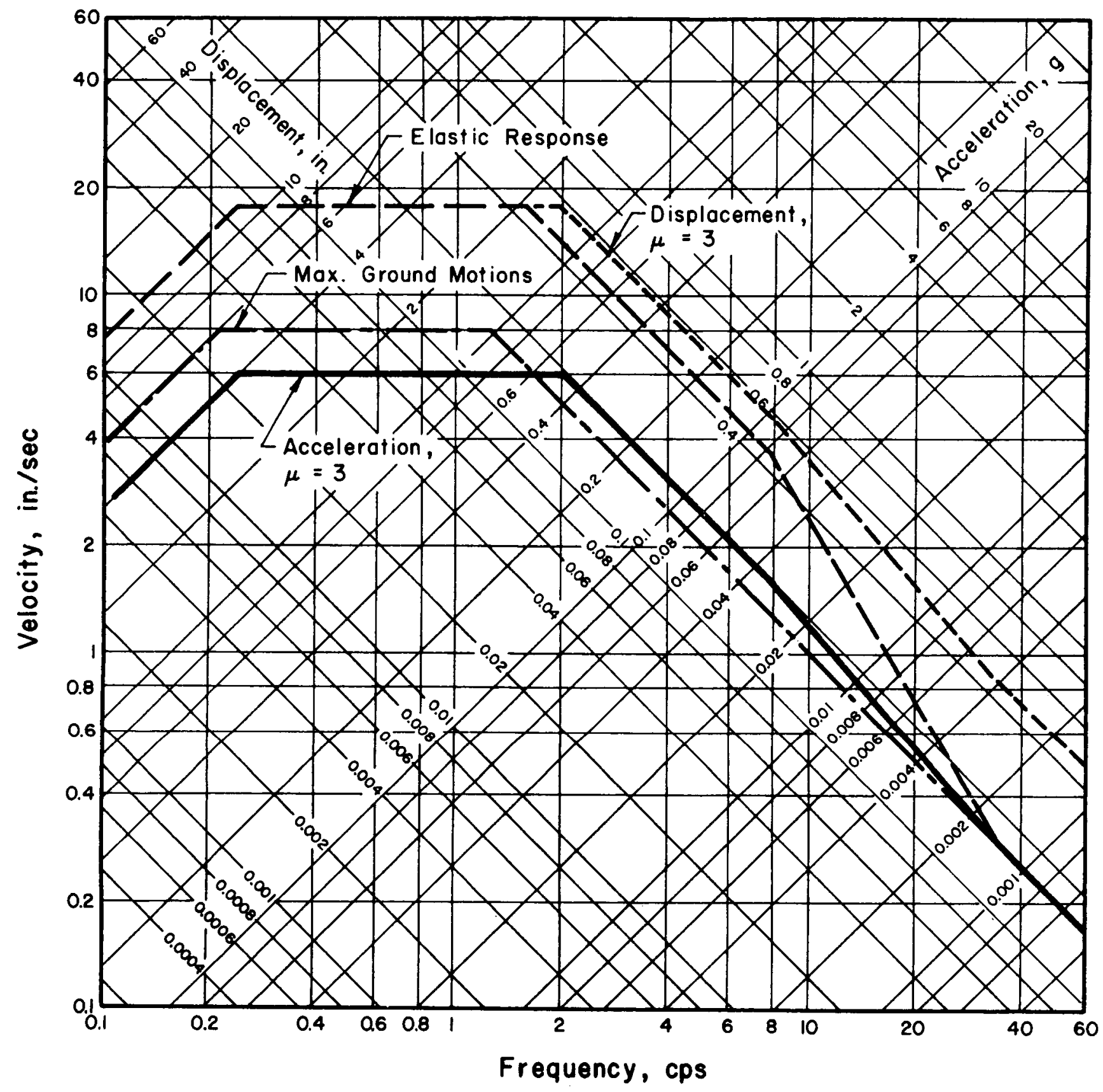

FIG. 5 ELASTIC AND INELASTIC DESIGN SPECTRA 